\title{
Endogenous Timing of Moves in Bertrand-Edgeworth Triopolies
}

\author{
Attila Tasnádi* \\ MTA-BCE "Lendület" Strategic Interactions Research Group, \\ Department of Mathematics, Corvinus University of Budapest ${ }^{\dagger}$
}

December 27, 2012

\begin{abstract}
We determine the endogenous order of moves in which the firms set their prices in the framework of a capacity-constrained Bertrand-Edgeworth triopoly. A threeperiod timing game that determines the period in which the firms announce their prices precedes the price-setting stage. We show for the non-trivial case (in which the Bertrand-Edgeworth triopoly has only an equilibrium in non-degenerated mixedstrategies) that the firm with the largest capacity sets its price first, while the two other firms set their prices later. Our result extends a finding by Deneckere and Kovenock (1992) from duopolies to triopolies. This extension was made possible by Hirata's (2009) recent advancements on the mixed-strategy equilibria of Bertrand-Edgeworth games.
\end{abstract}

Keywords: Bertrand-Edgeworth, price leadership, oligopoly, timing games.

JEL Classification Number: D43, L13.

\section{Introduction}

A challenging question for oligopoly theory and its applications is the determination of the right order of moves because this influences the market structure and its equilibrium behavior. In this paper we address the timing problem for price-setting games, in particular, within the framework of a homogenous good capacity-constrained Bertrand-Edgeworth triopoly. The key feature of these price-setting games is that the firms may serve less than the demand they are facing. The main difficulty with these models is that one has to consider mixed-strategy equilibria since for the interesting cases there is a lack of equilibrium in pure strategies. ${ }^{1}$

Deneckere and Kovenock (1992) determined the endogenous order of decisions in a homogeneous good Bertrand-Edgeworth duopoly game with capacity constraints. Their

\footnotetext{
${ }^{*}$ Financial support from the Hungarian Scientific Research Fund (OTKA K-101224) is gratefully acknowledged.

${ }^{\dagger}$ Fővám tér 8, 1093 Budapest, Hungary (e-mail: attila.tasnadi@uni-corvinus.hu)

${ }^{1}$ For more on Bertrand-Edgeworth games the reader is referred to Vives (1999).
} 
result was partially generalized from duopolies to oligopolies by Gangopadhyay (1993) who compared the simultaneous-move case with the purely sequential move case, which still did not determine the endogenous order of moves for the oligopolistic case. The main difficulty in solving the timing problem lies in the difficulty of handling the mixedstrategy equilibrium in Bertrand-Edgeworth games. Beckmann (1965), Levitan and Shubik (1972) Vives (1986) and Cheviakov and Hartwick (2005) determined the mixed-strategy equilbrium solutions under quite restrictive assumptions such as linear demand or identical firms. Under more general conditions the mixed-strategy equilibrium has been given in nonclosed form by Kreps and Scheinkman (1983), Davidson and Deneckere (1986), Osborne and Pitchik (1986) and Allen and Hellwig (1993) in the duopolistic setting.

The investigation of the triopolistic timing game has been made possible by recent characterizations of the mixed-strategy equilibrium of capacity-constrained BertrandEdgeworth triopolies by Hirata (2009) and independently by De Francesco and Salvadori (2010). Based on their characterizations we find that the large-capacity firm will emerge as the endogenous price leader, which extends a result on the duopolistic case obtained by Deneckere and Kovenock (1992). Timing of decisions within the price-setting framework usually results in known forms of price leadership, and therefore, we will also relate our results to the dominant firm model of price leadership.

In general, there is a growing literature on endogenous timing of decisions in oligopolies both in the price-setting and the quantity-setting framework. The first contributions in this direction were made by Gal-Or (1985), Dowrick (1986) and Boyer and Moreaux (1987) in works that compared the outcomes of exogenous timing duopoly games in order to find out whether the leader or the follower has a more advantageous position. The recent literature aims to solve the conflict concerning roles, and determines an endogenous order of moves under certain circumstances. Just to mention some important works from the large number of contributions we refer to Hamilton and Slutsky (1990), Deneckere and Kovenock (1992), van Damme and Hurkens (1999, 2004), Matsumura (1999, 2002), Dastidar and Furth (2005), Yano and Komatsubara $(2006,2012)$ and von Stengel (2010).

It is worthwile mentioning that another strand of the literature aims to generalize results from the Bertrand-Edgeworth duopoly game with deterministic demand to the case of demand uncertainty. For noteable results in this direction we refer to Hviid (1991), Reynolds and Wilson (2000), de Frutos and Fabra (2011) and Lepore (2012).

The remainder of the paper is organized as follows. Section 2 presents our framework and an important Lemma. Section 3 considers price-setting games with exogenously given orderings of moves. Section 4 determines the solution of our three-period timing game. Finally, Section 5 contains some concluding remarks.

\section{Framework and preliminary result}

Suppose that there are three firms on the market, where we shall denote the set of firms by $N=\{1,2,3\}$. We assume that the firms have zero unit costs $^{2}$ up to some positive capacity constraints. We shall denote by $k_{i}$ the capacity constraint of firm $i$ and by $K=\sum_{i=1}^{3} k_{i}$ the aggregate capacity of the firms. Let the capacity constraints be ordered decreasingly and in order to reduce the number of cases we also assume that the two firms with the smaller

\footnotetext{
${ }^{2}$ Since we are considering the production-to-order version of the Bertrand-Edgeworth game (that is, production takes place after the firms' prices are revealed), the real assumption here is that the firms have identical unit costs.
} 
capacities have identical capacities, i.e. $k_{1}>k_{2}=k_{3}$. We summarize the assumptions imposed on the triopolists' cost functions below:

Assumption 1. There are three firms on the market with zero unit costs and capacity constraints $k_{1}>k_{2}=k_{3}>0$.

We refer to firm 1 as the large firm and to firms 2 and 3 as the small firms. The demand is given by function $D$ on which we impose the following restrictions:

Assumption 2. The demand function $D$ intersects the horizontal axis at quantity $a$ and the vertical axis at price $b . D$ is strictly decreasing, concave and twice continuously differentiable on $(0, b)$; moreover, $D$ is right-continuous at 0 , left-continuous at $b$ and $D(p)=0$ for all $p \geq b$.

Clearly, any price-setting firm will not set its price above $b$. Let us denote by $P$ the inverse demand function. Thus, $P(q)=D^{-1}(q)$ for $0<q \leq a, P(0)=b$, and $P(q)=0$ for $q>a$. In addition, we shall denote by $p^{c}$ the market clearing price, i.e. $p^{c}=P(K)$.

Furthermore, we ensure that every firm will be active on the market by the next assumption:

Assumption 3. We assume that $K-k_{3}<a$.

Let $p_{i} \in[0, b]$ be the price decision of firm $i \in N$ and $t_{i} \in\{1,2,3\}$ be the time period in which firm $i$ annonces its price. In the first stage firms choose a time period for announcing their prices and in the second stage firms set their prices (already knowing in which period their opponents set their prices). The market opens after all firms have set their prices. This type of timing game is referred to as a timing game with observable delay (Hamilton and Slutsky, 1990). Of course, three periods are necessary and sufficient to allow for all possible orderings of moves in case of a triopoly. ${ }^{3}$

We have to specify a demand-allocating mechanism as a function of price and timing decisions made by the firms. In case of price ties we will assume that the demand is allocated first to firms announcing their prices in an earlier time period. This distinction ensures that we do not have to consider followers slightly undercutting the earlier movers' prices. Otherwise, the subgames will not always have an equilibrium and we would need to investigate $\varepsilon$-equilibrum solutions. Hence, assuming efficient rationing of consumers, the demand faced by a price-setting firm $i \in N$ is given by

$$
\Delta_{i}(\mathbf{t}, \mathbf{p})=\left(D\left(p_{i}\right)-\sum_{j \in N, p_{j}<p_{i}} k_{j}-\sum_{j \in N, p_{j}=p_{i}, t_{j}<t_{i}} k_{j}\right)^{+} \frac{k_{i}}{\sum_{j \in N, p_{j}=p_{i}, t_{j}=t_{i}} k_{j}} .
$$

Thus, firm $i \in N$ makes $\pi_{i}(\mathbf{t}, \mathbf{p})=p_{i} \min \left\{k_{i}, \Delta_{i}(\mathbf{t}, \mathbf{p})\right\}$ profit.

We shall denote by $p_{i}^{m}$ the unique revenue maximizing price on the residual demand curve $D_{i}^{r}(p)=\left(D(p)-K+k_{i}\right)^{+}$and by $q_{i}^{m}$ the corresponding unique revenue maximizing output on the inverse residual demand curve $P_{i}^{r}$, i.e. $p_{i}^{m}=\arg \max _{p \in[0, b]} p D_{i}^{r}(p)$ and $q_{i}^{m}=\arg \max _{q \in[0, a]} q P_{i}^{r}(q)$ for any $i \in N$. Of course, $q_{i}^{m}=D_{i}^{r}\left(p_{i}^{m}\right)$. Clearly, $p^{c}$ and $p_{i}^{m}$ are well defined whenever Assumptions 1-3 are satisfied. Furthermore, it can be checked that $p_{1}^{m}>p_{2}^{m}=p_{3}^{m}$ because of Assumptions 1-3. Let $\bar{\pi}_{i}=\pi_{i}^{r}\left(p_{i}^{m}\right)$, where $\pi_{i}^{r}(p)=p D_{i}^{r}(p)$. Note that Assumption 3 also ensures that $p_{i}^{m}>0$ and $\bar{\pi}_{i}>0$.

\footnotetext{
${ }^{3}$ The special triopolistic case of only two possible periods has been considered in Tasnádi (2010). However, at least three periods are needed to allow for the emergence of all possible orderings.
} 
If $k_{i} \leq q_{i}^{m}$, then we will say that firm $i \in N$ has scarce capacity, while otherwise we will say that firm $i \in N$ has sufficient capacity. Note that a firm with scarce capacity will be eager to produce at its capacity limit. It can be verified that condition $k_{i} \leq q_{i}^{m}$ is equivalent to $p^{c} \geq p_{i}^{m}$. Let us denote by $p_{i}^{d} \in\left[0, p_{i}^{m}\right]$ the smallest price for which $p_{i}^{d} \min \left\{k_{i}, D\left(p_{i}^{d}\right)\right\}=p_{i}^{m} D_{i}^{r}\left(p_{i}^{m}\right)$ whenever this equation has a solution, which is the case, for instance, if firm $i$ has sufficient capacity (implying $\left.p^{c}<p_{i}^{d}<p_{i}^{m}\right)$. At price $p_{i}^{d}$ firm $i$ is indifferent to whether serving residual demand at price level $p_{i}^{m}$ or selling $\min \left\{k_{i}, D\left(p_{i}^{d}\right)\right\}$ at the lower price level $p_{i}^{d}$. We will need the following Lemma established for the two firm case by Deneckere and Kovenock (1992) and stated by Hirata (2009) for the triopolistic case.

Lemma 1. Suppose that firm $i$ and $j$ have both sufficient capacity and that Assumptions 1,2 and 3 are satisfied. If $i<j$, then $p_{i}^{d} \geq p_{j}^{d}$. In addition, if $k_{i}>k_{j}$, then $p_{i}^{d}>p_{j}^{d}$.

\section{$3 \quad$ Exogenously given order of moves}

In this section we investigate a variation of the capacity-constrained Bertrand-Edgeworth game with three firms in which the firms can announce their price decisions in one of three subsequent periods. The two-stage game with just two firms has been investigated by Deneckere and Kovenock (1992). They found for the duopolistic case with identical unit costs that the large capacity firm moves first, while the small capacity firm second. ${ }^{4}$ Recent characterizations of the mixed-strategy equilibrium of capacity-constrained BertrandEdgeworth oligopolies by Hirata (2009) and by De Francesco and Salvadori (2010) make it possible to extend Deneckere's and Kovenock's (1992) result from duopolies to triopolies.

Taking Assumption 1 and that the firms can set their prices in three periods into consideration, we have to investigate six different games with exogenously given orderings of moves:

(i) The large firm is the single exogenously given first mover,

(ii) the large firm is the single exogenously given last mover,

(iii) one of the small firms is the single exogenously given first mover and the other two firms move simultaneously,

(iv) one of the small firms is the single exogenously given final mover and the other two firms move simultaneously,

(v) a small firm is the exogenously given first mover, the large firm the exogenously given second mover and the other small firm the exogenously given third mover,

(vi) the three firms move in the same period.

Case (vi) leads to the simultaneous-move price-setting game analyzed by Hirata (2009) and De Francesco and Salvadori (2010). If the simultaneous-move game has an equilibrium in pure strategies, then we know that firms make either zero profits or produce all at their capacity limits in a pure-strategy equilibrium, in which case it can be checked that for any ordering of moves we will have the same outcome in cases (i)-(vi). Hence, the timing game is only of real interest if the simultaneous-move price-setting game does not have an equilibrium in pure strategies, i.e Assumption 4 is satisfied.

\footnotetext{
${ }^{4}$ They also investigated the case of different unit costs.
} 
Assumption 4. $p_{1}^{m}>p^{c}$.

We know from Hirata (2009) and De Francesco and Salvadori (2010) for case (vi) that firm 1's expected profit equals $\bar{\pi}_{1}$, while firm 2's and 3's expected profits equal $p_{1}^{d} k_{2}=p_{1}^{d} k_{3}$ under our assumptions. We will treat cases (i)-(v) in separate propositions.

Proposition 1. Under efficient rationing and Assumptions 1-4 if the large firm is the exogenously given first mover, then the unique subgame-perfect equilibrium prices and profits are given by

$$
\left(p_{1}^{*}, p_{2}^{*}, p_{3}^{*}\right)=\left(p_{1}^{m}, p_{1}^{m}, p_{1}^{m}\right) \text { and }\left(\pi_{1}^{*}, \pi_{2}^{*}, \pi_{3}^{*}\right)=\left(\bar{\pi}_{1}, p_{1}^{m} k_{2}, p_{1}^{m} k_{3}\right) .
$$

Proof. Clearly, firm 1 sets price $p_{1} \in\left[p_{1}^{d}, b\right)$. Suppose that $p_{i}>p_{1}$ for at least one small firm $i \in\{2,3\}$. If $p_{i}>p_{j}$, where $j$ denotes the other small firm $(i \neq j$ and $i, j \in\{2,3\})$, then firm $i$ would not earn more profit than $\bar{\pi}_{i}=p_{i}^{d} k_{i}$, which is less than $p_{1}^{d} k_{i} \leq p_{1} k_{i}$. Hence, firm $i$ would benefit from switching to price $p_{1}$. Switching to price $p_{1}$ is also beneficial if $p_{2}=p_{3}>p_{1}$ and the small firms do not sell anything at all. If the small firms face positive residual demand at price $p_{2}=p_{3}>p_{1}$ and the small firms are moving in the same period, then both small firms would benefit from unilaterally undercutting the other small firm's price. If the small firms face positive residual demand at price $p_{2}=p_{3}>p_{1}$ and the small firms move in different periods, then the first moving small firm would serve residual demand, and therefore it would be better of by setting price $p_{1}$.

From the previous paragraph we know that the small firms do not set prices above $p_{1}$, and therefore the large firm faces residual demand at price $p_{1}$. Hence, by maximizing profits with respect to its residual demand curce it sets price $p_{1}^{m}$. Therefore, in any possible purestrategy equilibrium the small firms match the large firm's price, ${ }^{5}$ i.e $p_{2}=p_{3}=p_{1}$, and it can be checked that this price profile corresponds to an equilibrium in pure strategies.

Proposition 1 delivers a partial game-theoretic microfoundation of Forchheimer's model of dominant firm price leadership in case of a special exogenously given ordering of moves. We will see later that the ordering assumed in Proposition 1 can be endogenized.

Turning to case (ii) in which the large firm is the sole last mover, we will see that if the large firm is indifferent between matching a small firm's price or serving residual demand, then in a subgame-perfect equilibrium it has to serve residual demand, and thus sets a higher price than the small firms. As it will be evident from the proof of Proposition 2, the definition of the subgame-perfect Nash equilibrium implies that this can be the only possible response of the large firm although the small firms cannot enforce in stage two that the large firm will not match their price. Anyway to overcome this kind of uncertainty the small firms could enforce an outcome close to the one stated in Proposition 2 by setting a slightly lower price than either $p_{1}^{d}$ or $p_{1}^{u}$, where $p_{1}^{u} \in\left(p_{1}^{d}, p_{1}^{m}\right]$ is defined by $p_{1}^{u} \min \left\{k_{1},\left(D\left(p_{1}^{u}\right)-k_{2}\right)^{+}\right\}=\bar{\pi}_{1} .{ }^{6}$ This latter defensive behavior would result in an $\varepsilon$-equilibrium on the market.

Proposition 2. Under efficient rationing and Assumptions 1-4 if the large firm is the exogenously given sole last mover, we have to distinguish between the two main cases specified below.

\footnotetext{
${ }^{5}$ More precisely, this holds true unless $p_{1}>P\left(k_{2}+k_{3}\right)$. However, firm 1 will definitely not set a price above $P\left(k_{2}+k_{3}\right)$ since then the small-capacity firms will not set a price higher than $p_{1}$, and thus, firm 1 will not sell anything at all.

${ }^{6}$ Price $p_{1}^{u}$ can be interpreted as the price at which the large-capacity firm is indifferent between serving residual demand or being undercut by only one small-capacity firm.
} 
1. If $k_{1} \leq D\left(p_{1}^{d}\right)-k_{2}$, then the subgame-perfect equilibrium prices and profits are given by

$$
\left(p_{1}^{*}, p_{2}^{*}, p_{3}^{*}\right)=\left(p_{1}^{m}, p_{1}^{d}, p_{1}^{d}\right) \text { and }\left(\pi_{1}^{*}, \pi_{2}^{*}, \pi_{3}^{*}\right)=\left(\bar{\pi}_{1}, p_{1}^{d} k_{2}, p_{1}^{d} k_{3}\right)
$$

for any ordering of moves of the small firms.

2. If $k_{1}>D\left(p_{1}^{d}\right)-k_{2}$ and

(a) the small firms are moving simultaneously, then we have two possible subgameperfect equilibria with associated equilibrium prices and profits given by

$$
\begin{aligned}
& \left(p_{1}^{*}, p_{2}^{*}, p_{3}^{*}\right)=\left(p_{1}^{m}, p_{1}^{d}, p_{1}^{u}\right) \quad \text { and } \quad\left(\pi_{1}^{*}, \pi_{2}^{*}, \pi_{3}^{*}\right)=\left(\bar{\pi}_{1}, p_{1}^{d} k_{2}, p_{1}^{u} k_{3}\right), \text { and } \\
& \left(p_{1}^{*}, p_{2}^{*}, p_{3}^{*}\right)=\left(p_{1}^{m}, p_{1}^{u}, p_{1}^{d}\right) \quad \text { and } \quad\left(\pi_{1}^{*}, \pi_{2}^{*}, \pi_{3}^{*}\right)=\left(\bar{\pi}_{1}, p_{1}^{u} k_{2}, p_{1}^{d} k_{3}\right) ;
\end{aligned}
$$

(b) firm 2 is the sole first mover, then the subgame-perfect equilibrium prices and profits are given by

$$
\left(p_{1}^{*}, p_{2}^{*}, p_{3}^{*}\right)=\left(p_{1}^{m}, p_{1}^{u}, p_{1}^{d}\right) \text { and }\left(\pi_{1}^{*}, \pi_{2}^{*}, \pi_{3}^{*}\right)=\left(\bar{\pi}_{1}, p_{1}^{u} k_{2}, p_{1}^{d} k_{3}\right) ;
$$

(c) firm 3 is the sole first mover, then the subgame-perfect equilibrium prices and profits are given by

$$
\left(p_{1}^{*}, p_{2}^{*}, p_{3}^{*}\right)=\left(p_{1}^{m}, p_{1}^{d}, p_{1}^{u}\right) \text { and }\left(\pi_{1}^{*}, \pi_{2}^{*}, \pi_{3}^{*}\right)=\left(\bar{\pi}_{1}, p_{1}^{d} k_{2}, p_{1}^{u} k_{3}\right) .
$$

Proof. Since firm 1 never sets a price below $p_{1}^{d}$, the lowest price firms 2 and 3 might set in an equilibrium is $p_{1}^{d}$. Observe that in a pure-strategy subgame-perfect equilibrium at least one of the two small firms must set price $p_{1}^{d}$, since otherwise firm 1 will not set a higher price than the larger one of the two small firms' prices, and therefore either the small firm setting the highest price would benefit from switching to price $p_{1}^{d}$ or one of the small firms could benefit from a unilateral price decrease.

Suppose in case of $k_{1}<D\left(p_{1}^{d}\right)-k_{i}$ that small firm $i$ sets price $p_{1}^{d}$, while the other small firm $j$ sets a price $p_{j}$ above $p_{1}^{d}$. Then firm 1 would be better off by setting a price beween $p_{1}^{d}$ and $p_{j}$, since at prices slightly higher than $p_{1}^{d}$ (but lower than $p_{j}$ ) it can sell its entire capacity and make more profits than $\bar{\pi}_{1}$. Thus, firm $j$ makes $\pi_{j}^{r}\left(p_{j}\right)$ profits, which is less than $p_{1}^{d} k_{j}$; a contradiction. Hence, in case of $k_{1}<D\left(p_{1}^{d}\right)-k_{i}$ the two small firms set price $p_{1}^{d}$ if their are moving simultaneously or sequentially before the large firm, which sets price $p_{1}^{m}$.

In contrast to the previous case in case of $k_{1} \geq D\left(p_{1}^{d}\right)-k_{i}$ firm $j$ could set its first-stage price to $p_{1}^{u}$ because maximizing profits with respect to the demand function $D(p)-k_{i}$ within interval $\left[p_{1}^{d}, p_{1}^{u}\right]$ would not result in higher profits than $\bar{\pi}_{1}$ for the large firm. However, it has to be verified that there exists a value $p_{1}^{u} \in\left[p_{1}^{d}, p_{1}^{m}\right)$ satisfying $p_{1}^{u} \min \left\{k_{1},\left(D\left(p_{1}^{u}\right)-k_{2}\right)^{+}\right\}=\bar{\pi}_{1}$. Let $f(p)=p \min \left\{k_{1},\left(D(p)-k_{2}\right)^{+}\right\}$. Since $k_{1} \geq D\left(p_{1}^{d}\right)-k_{i}$ it can be verified that $f\left(p_{1}^{d}\right) \leq \bar{\pi}_{1}=p_{1}^{d} \min \left\{k_{1}, D\left(p_{1}^{d}\right)\right\}, f^{\prime}(p)>0$ on $\left[p_{1}^{d}, p_{1}^{m}\right]$ and $f\left(p_{1}^{m}\right)>\bar{\pi}_{1}=p_{1}^{m} \min \left\{k_{1},\left(D\left(p_{1}^{m}\right)-k_{2}-k_{3}\right)^{+}\right\}$. Hence, there exists a unique $p_{1}^{u} \in\left[p_{1}^{d}, p_{1}^{m}\right]$ satisfying $f\left(p_{1}^{u}\right)=\bar{\pi}_{1}$. Obsevere that $p_{1}^{u}=p_{1}^{d}$ if and only if $k_{1}=D\left(p_{1}^{d}\right)-k_{i}$, and therefore in this special case the two small firms will set both price $p_{1}^{d}$. We conclude that in case of $k_{1}>D\left(p_{1}^{d}\right)-k_{i}$ we obtain two asymmetric subgame-perfect equilibria if the two small firms move simultaneously and one subgame-perfect equilibrium if the two small firms move sequentially. It can be checked that the resulting strategy profiles determine the pure-strategy subgame-perfect Nash equilibria stated in the proposition. 
The result of Proposition 2 is analogous to case (c) of Theorem 3 in Deneckere and Kovenock (1992) in the sense that the small firms set low prices so that they will not be undercut by the large firm.

We continue our analysis with investigating the case in which a small firm's move is followed by a simultaneous move of the large firm and the other small firm.

Proposition 3. Under efficient rationing and Assumptions 1-4 if one of the small firms, say firm 3, is the exogenously given first mover and the other two firms move simultaneously, then the subgame-perfect equilibrium prices and expected profits are given in case of $k_{1} \leq D\left(p_{1}^{d}\right)-k_{2}$ by

$$
\left(p_{1}^{*}, p_{2}^{*}, p_{3}^{*}\right)=\left(X_{1}^{*}, X_{2}^{*}, p_{1}^{d}\right) \text { and }\left(E \pi_{1}^{*}, E \pi_{2}^{*}, \pi_{3}^{*}\right)=\left(\bar{\pi}_{1}, p_{1}^{d} k_{2}, p_{1}^{d} k_{3}\right),
$$

and in case of $k_{1}>D\left(p_{1}^{d}\right)-k_{2}$ by

$$
\left(p_{1}^{*}, p_{2}^{*}, p_{3}^{*}\right)=\left(X_{1}^{*}, X_{2}^{*}, p_{1}^{d}\right) \text { and }\left(E \pi_{1}^{*}, E \pi_{2}^{*}, \pi_{3}^{*}\right)=\left(\bar{\pi}_{1}, p_{1}^{u} k_{2}, p_{1}^{d} k_{3}\right),
$$

where the independent random variables $X_{1}^{*}, X_{2}^{*}$ describing the prices set by firms 1 and 2 are distributed according to the mixed-strategy profile $\left(\varphi_{1}^{*}, \varphi_{2}^{*}\right)$, which constitutes a mixedstrategy equilibrium of a Bertrand-Edgeworth duopoly game with demand function $(D(p)-$ $\left.k_{3}\right)^{+} .7$

Proof. By the exogenously given ordering of moves firm 3 sets price $p_{3} \in[0, b]$ in stage 1, and thereafter, firms 1 and 2 play a simultaneous-move Bertrand-Edgeworth duopoly game with respect to the demand function

$$
\widetilde{D}(p)= \begin{cases}\left(D(p)-k_{3}\right)^{+} & \text {if } p>p_{3} \text { and } \\ D(p) & \text { if } p \leq p_{3}\end{cases}
$$

which is discontinuous at $p_{3}$ if $p_{3} \in[0, b)$. The subgame has an equilibrium $\left(\varphi_{1}, \varphi_{2}\right)$ in mixed strategies by Osborne and Pitchik (1986). ${ }^{8}$ Let $\bar{p}_{i}=\sup \operatorname{supp}\left(\varphi_{i}\right)$ and $\underline{p}_{i}=\inf$ $\operatorname{supp}\left(\varphi_{i}\right)$ for each $i \in\{1,2\}$.

Since any price $p_{1}<p_{1}^{d}$ is dominated by price $p_{1}^{m}$ for firm 1 we must have $\underline{p}_{1} \geq p_{1}^{d}$. Hence, firm 3 will not set its price $p_{3}$ below $p_{1}^{d}$ in a subgame-perfect equilibrium in stage 1 , because otherwise it would be better off by setting a price between $p_{3}$ and $p_{1}^{d}$.

Assume that $p_{3} \geq p_{1}^{m}$. Suppose that $\bar{p}_{1}>p_{3}$ or $\bar{p}_{2}>p_{3}$ for which case we consider two subcases. First, if $\bar{p}_{i}>\bar{p}_{j}$, where $i, j \in\{1,2\}$ and $i \neq j$, then firm $i$ 's expected profit equals $\pi_{i}^{r}\left(\bar{p}_{i}\right)$, which is less than $\pi_{i}^{r}\left(p_{i}^{m}\right)$, and therefore $\bar{p}_{i}>\bar{p}_{j}$ cannot be the case. Second, suppose that $\bar{p}_{1}=\bar{p}_{2}$. Observe that both equilibrium strategies $\varphi_{1}$ and $\varphi_{2}$ cannot have an atom at price $\bar{p}_{1}=\bar{p}_{2}$, since otherwise both firms could benefit from unilaterally shifting the probability mass from price $\bar{p}_{1}=\bar{p}_{2}$ to a price slightly below $\bar{p}_{1}=\bar{p}_{2}$. Thus, we see that the strategy of at most one firm, say firm $i \in\{1,2\}$, can have an atom at price $\bar{p}_{1}=\bar{p}_{2}$, and therefore its expected profit equals $\pi_{i}^{r}\left(\bar{p}_{i}\right)<\pi_{i}^{r}\left(p_{i}^{m}\right)$. Hence, $\bar{p}_{1}=\bar{p}_{2}>p_{3}$ cannot be the case if $\left(\varphi_{1}, \varphi_{2}\right)$ is an equilibrium of the subgame. So far we obtained that in case of $p_{3} \geq p_{1}^{m}$ we must have $\bar{p}_{1} \leq p_{3}$ and $\bar{p}_{2} \leq p_{3}$. However, then firm 3 serves its residual

\footnotetext{
${ }^{7}$ Henceforth in this section, we emphasize that we have determined the firms' nondeterministic expected profits by writing $E \pi_{i}$, whereas we simply write $\pi_{i}$ if profits are deterministic.

${ }^{8}$ Osborne and Pitchik (1986) mention the case of discontinuous, but left-continuous demand functions in Section 5. For recent advancements on the mixed-strategy equilibrium of the Bertrand-Edgeworth duopoly game we refer to Bagh (2010).
} 
demand $D_{3}^{r}\left(p_{3}\right)$, which is strictly dominated by a price $p_{1}^{d}-\varepsilon$ for a sufficiently small $\varepsilon>0$. Therefore, firm 3 never sets a price greater than or equal to $p_{1}^{m}$.

We have already shown that in the first stage firm 3 selects a price from interval $\left[p_{1}^{d}, p_{1}^{m}\right)$. Assume that firm 3 sets price $p_{3}=p_{1}^{d}$. In determining the equilibrium of the subgame, we consider the modified Bertrand-Edgeworth duopoly game with capacity constraints $k_{1}>$ $k_{2}$ and demand function $\left(D-k_{3}\right)^{+}$, which by Deneckere and Kovenock (1992, Theorem 1) has a unique equilibrium in non-degenerate mixed strategies for which $\left[\underline{p}_{1}, \bar{p}_{1}\right]=\left[\underline{p}_{2}, \bar{p}_{2}\right]=$ $\left[p_{1}^{d}, p_{1}^{m}\right]$ if $k_{1} \leq D\left(p_{1}^{d}\right)-k_{2}$, and $\left[\underline{p}_{1}, \bar{p}_{1}\right]=\left[\underline{p}_{2}, \bar{p}_{2}\right]=\left[p_{1}^{u}, p_{1}^{m}\right]$ if $k_{1}>D\left(p_{1}^{\bar{d}}\right)-k_{2}$. Moreover, the expected profits of firms 1 and 2 equal $\bar{\pi}_{1}$ and $\underline{p}_{2} k_{2}$, respectively. In addition, only price $p_{1}^{m}$ is played with positive probability by firm 1 . Since $\left(D-k_{3}\right)^{+}=\widetilde{D}$ for prices greater than $p_{1}^{d}$, price $p_{1}^{d}$ will be played with probability zero and the second movers cannot achieve higher profits by unilaterally switching to price $p_{1}^{d}$, the mixed-strategy equilibrium of the modified game will also be a mixed-strategy equilibrium of our subgame. ${ }^{9}$ Moreover, it has to be the unique equilibrium of the subgame by the way how the mixed-strategy equilibrium has to be calculated. ${ }^{10}$

Finally, we turn to the case of $p_{3} \in\left(p_{1}^{d}, p_{1}^{m}\right)$. Suppose that firm 3 can achieve a higher profit by setting price $p_{3} \in\left(p_{1}^{d}, p_{1}^{m}\right)$ than by setting price $p_{1}^{d}$, where the latter price results in $p_{1}^{d} k_{3}$ profits. We divide our analysis into two subcases: (a) $\bar{p}_{1}>p_{3}$ and (b) $\bar{p}_{1} \leq p_{3}$. In Subcase (a) we must have $\bar{p}_{2} \leq \bar{p}_{1}$, since otherwise $\pi_{2}\left(\varphi_{1}, \bar{p}_{2}, p_{3}\right)=\pi_{2}^{r}\left(\bar{p}_{2}\right) \leq \pi_{2}^{r}\left(p_{2}^{m}\right)=$ $p_{2}^{d} k_{2}<p_{1}^{d} k_{2}$, which cannot be the case in an equilibrium. Therefore, it follows that $\bar{p}_{1}=p_{1}^{m}$, which in turn implies that we cannot have $\underline{p}_{2}>p_{1}^{d}$, since otherwise firm 1 would benefit from switching to $p_{1} \in\left(p_{1}^{d}, \min \left\{\underline{p}_{2}, p_{3}\right\}\right)$ from $\varphi_{1}$. Hence, we must have $\underline{p}_{2}=p_{1}^{d}$, and thus $\underline{p}_{1}=p_{1}^{d}$. Employing our assumption that firm 3 is better off by setting a price above $p_{1}^{d}$ than by setting price $p_{1}^{d}$, we obtain that $\pi_{3}\left(\varphi_{1}, \varphi_{2}, p_{3}\right)>p_{1}^{d} k_{3}=p_{1}^{d} k_{2}=\pi_{2}\left(\varphi_{1}, \varphi_{2}, p_{3}\right){ }^{11}$ However, $\pi_{2}\left(\varphi_{1}, p_{3}, p_{3}\right) \geq \pi_{3}\left(\varphi_{1}, \varphi_{2}, p_{3}\right)>\pi_{2}\left(\varphi_{1}, \varphi_{2}, p_{3}\right)$, where the first inequality follows from the tie-breaking rule, is in contradiction with $\left(\varphi_{1}, \varphi_{2}\right)$ constituting an equilibrium of the subgame. This means that in Subcase (a) firm 3 sets price $p_{1}^{d}$. Turning to Subcase (b), it can be verified that $\bar{p}_{1} \leq p_{3}$ implies $\bar{p}_{2} \leq p_{3}$, an therefore setting price $p_{3}$ is worse than setting price $p_{1}^{d}$ for firm 3 . Concerning both subcases, we conclude that the first stage equilibrium action of firm 3 is $p_{3}^{*}=p_{1}^{d}$.

From Proposition 3 we see that the small firm moving first has to set a lower price and that the other small firm could be better off.

Now we shall turn to the case in which the simultaneous moves of the large firm and a small firm is followed by the move of the other small firm.

Proposition 4. Under efficient rationing and Assumptions 1-4 if one of the small firms, say firm 3, is the exogenously given last mover and the other two firms move simultaneously, then the subgame-perfect equilibrium prices and profits are given in case of $k_{1} \leq D\left(p_{1}^{d}\right)-k_{2}$ by

$$
\begin{aligned}
\left(p_{1}^{*}, p_{2}^{*}, p_{3}^{*}\right) & =\left(X_{1}^{*}, X_{2}^{*}, E \max \left\{X_{1}^{*}, X_{2}^{*}\right\}\right) \text { and } \\
\left(E \pi_{1}^{*}, E \pi_{2}^{*}, E \pi_{3}^{*}\right) & =\left(\bar{\pi}_{1}, p_{1}^{d} k_{2}, E \max \left\{X_{1}^{*}, X_{2}^{*}\right\} k_{3}\right),
\end{aligned}
$$

\footnotetext{
${ }^{9}$ Since $\widetilde{D}\left(p_{1}^{d}\right)>\left(D-k_{3}\right)^{+}\left(p_{1}^{d}\right)$ and $k_{1}>\left(D-k_{3}\right)^{+}\left(p_{1}^{d}\right)$ in case of $k_{1}>D\left(p_{1}^{d}\right)-k_{2}$, it should be emphasized that firm 1 still makes only $\bar{\pi}_{1}$ profit when setting price $p_{1}^{d}$.

${ }^{10}$ See Kreps and Scheinkman (1983), Osborne and Pitchik (1986) and Deneckere and Kovenock (1992).

${ }^{11}$ For the last equality we need that $\varphi_{1}$ does not have an atom at price $p_{1}^{d}$, which can be shown easily by contradiction.
} 
and in case of $k_{1}>D\left(p_{1}^{d}\right)-k_{2}$ by

$$
\begin{aligned}
\left(p_{1}^{*}, p_{2}^{*}, p_{3}^{*}\right) & =\left(X_{1}^{*}, X_{2}^{*}, E \max \left\{X_{1}^{*}, X_{2}^{*}\right\}\right) \text { and } \\
\left(E \pi_{1}^{*}, E \pi_{2}^{*}, E \pi_{3}^{*}\right) & =\left(\bar{\pi}_{1}, p_{1}^{u} k_{2}, E \max \left\{X_{1}^{*}, X_{2}^{*}\right\} k_{3}\right),
\end{aligned}
$$

where the independent random variables $X_{1}^{*}, X_{2}^{*}$ describing the prices set by firms 1 and 2 , respectively, are distributed according to the mixed-strategy profile $\left(\varphi_{1}^{*}, \varphi_{2}^{*}\right)$, which constitutes a mixed-strategy equilibrium price profile of a Bertrand-Edgeworth duopoly game with demand function $\left(D(p)-k_{3}\right)^{+}$. In addition, we know that $p_{1}^{d} k_{3}<E \max \left\{X_{1}^{*}, X_{2}^{*}\right\} k_{3}<$ $p_{1}^{m} k_{3}$ or $p_{1}^{u} k_{3}<E \max \left\{X_{1}^{*}, X_{2}^{*}\right\} k_{3}<p_{1}^{m} k_{3}$ depending on the case.

Proof. Firm 3 serves its residual demand $D_{3}^{r}$ in stage 2 if $p_{3}>\max \left\{p_{1}, p_{2}\right\}$. Since firm 1 never sets a price below $p_{1}^{d}$ and $p_{3}^{m} D_{3}^{r}\left(p_{3}^{m}\right)=p_{3}^{d} k_{3}<p_{1}^{d} k_{3}$ firm 3 never sets a price higher than $\max \left\{p_{1}, p_{2}\right\}$. Hence, firms 1 and 2 face demand curve $\left(D(p)-k_{3}\right)^{+}$in stage 1. Finally, by taking the results on Bertrand-Edgeworth duopolies (e.g. Deneckere and Kovenock, 1992) into consideration, we obtain the statements of the proposition.

Observe that the small firm being the follower is better off than the other small firm moving simultaneously with the large firm under the Assumptions of Proposition 4.

Finally, we turn to the case in which the large firm moves between the two small firms.

Proposition 5. Under efficient rationing and Assumptions 1-4 if a small firm, say firm 3 , is the exogenously given first mover, the large firm the exogenously given second mover and the other small firm the exogenously given third mover, then we have to distinguish between the following two cases.

1. If $k_{1} \leq D\left(p_{1}^{d}\right)-k_{2}$, then the subgame-perfect equilibrium prices and profits are given by

$$
\begin{aligned}
\left(p_{1}^{*}, p_{2}^{*}, p_{3}^{*}\right) & =\left(p_{1}^{m}, p_{1}^{m}, p_{1}^{d}\right) \text { and } \\
\left(\pi_{1}^{*}, \pi_{2}^{*}, \pi_{3}^{*}\right) & =\left(\bar{\pi}_{1}, p_{1}^{m} k_{2}, p_{1}^{d} k_{3}\right) .
\end{aligned}
$$

2. If $k_{1}>D\left(p_{1}^{d}\right)-k_{2}$, then the subgame-perfect equilibrium prices and profits are given by

$$
\begin{aligned}
\left(p_{1}^{*}, p_{2}^{*}, p_{3}^{*}\right) & =\left(p_{1}^{m}, p_{1}^{m}, p_{1}^{u}\right) \text { and } \\
\left(\pi_{1}^{*}, \pi_{2}^{*}, \pi_{3}^{*}\right) & =\left(\bar{\pi}_{1}, p_{1}^{m} k_{2}, p_{1}^{u} k_{3}\right) .
\end{aligned}
$$

Proof. Clearly, in period 2 firm 1 will never set a price below $p_{1}^{d}$ and then the same holds true for firm 2 because of the employed tie-breaking rule. Therefore, firm 3 will neither set a price $p_{3}$ below $p_{1}^{d}$, since otherwise it would be better off by setting a price between $p_{3}$ and $p_{1}^{d}$. For a similar reason in a subgame-perfect equilibrium firm 3 does not serve its residual demand (which would happen if it sets one of the highest prices) since it would be better off by setting price $p_{1}^{d}-\varepsilon$, where $\varepsilon$ is a sufficiently small positive value.

Observe that in a subgame-perfect equilibrium $p_{2}$, the price set by firm 2 , cannot be higher than firm 1's price because this would imply that either firm 2 or firm 3 must serve residual remand. However, serving residual demand can be avoided by setting price $p_{1}^{d}$ in case of firm 2 and by setting price $p_{1}^{d}-\varepsilon$ in case of firm 3 , which would result in more profits for the respective small firm. Hence, firm 1 has to serve residual demand and firm 3 sets the highest possible price in period 1, which still does not result in serving its residual demand. Observe that therefore the same two cases as in Propositions 2-4 emerge. Thus, firm 3 either sets price $p_{1}^{d}$ or $p_{1}^{u}$, firm 1 set price $p_{1}^{m}$ and firm 2 follows with price $p_{1}^{m}$. 


\section{Endogenous order of moves}

In this section we determine the ordering in which the firms announce their price decisions. First, the firms decide whether they make their price announcements in period 1,2 or 3 . Second, observing when the other firms have set their prices, the firms play the selected price-setting game corresponding to cases (i)-(vi). That is, a 'game with observable delay' is played in the terminology of Hamilton and Slutsky (1990).

Based on Tables 1 and 2, containing the equilibrium payoffs described in Propositions 1-5, we can determine the equilibrium timing decisions of the firms. The two different tables correspond to the case distinctions made in Propositions 2-5. In both tables the row player is firm 2, the column player is firm 3 and the three rows of each cell of the table correspond to the respective timing decision of firm 1 . In addition, Table 2 contains two entries in some rows of some cells because Proposition 2 allows for two possible equilibria in case of $k_{1}>D\left(p_{1}^{d}\right)-k_{2}$. In both tables $\widetilde{p}$ stands for the expected price of the small-capacity firm when playing a mixed-strategy equilibrium according to Proposition 3.

\begin{tabular}{|c|c|c|c|}
\hline Firm 2\3 & Period 1 & Period 2 & Period 3 \\
\hline \multirow{3}{*}{ Period 1 } & $\left(\bar{\pi}_{1}, p_{1}^{d} k_{2}, p_{1}^{d} k_{3}\right)$ & $\left(\bar{\pi}_{1}, p_{1}^{d} k_{2}, \widetilde{p} k_{3}\right)$ & $\left(\bar{\pi}_{1}, p_{1}^{d} k_{2}, \widetilde{p} k_{3}\right)$ \\
& $\left(\bar{\pi}_{1}, p_{1}^{d} k_{2}, p_{1}^{d} k_{3}\right)$ & $\left(\bar{\pi}_{1}, p_{1}^{d} k_{2}, p_{1}^{d} k_{3}\right)$ & $\left(\bar{\pi}_{1}, p_{1}^{d} k_{2}, p_{1}^{m} k_{3}\right)$ \\
& $\left(\bar{\pi}_{1}, p_{1}^{d} k_{2}, p_{1}^{d} k_{3}\right)$ & $\left(\bar{\pi}_{1}, p_{1}^{d} k_{2}, p_{1}^{d} k_{3}\right)$ & $\left(\bar{\pi}_{1}, p_{1}^{d} k_{2}, p_{1}^{d} k_{3}\right)$ \\
\hline \multirow{3}{*}{ Period 2 } & $\left(\bar{\pi}_{1}, \widetilde{p} k_{2}, p_{1}^{d} k_{3}\right)$ & $\left(\bar{\pi}_{1}, p_{1}^{m} k_{2}, p_{1}^{m} k_{3}\right)$ & $\left(\bar{\pi}_{1}, p_{1}^{m} k_{2}, p_{1}^{m} k_{3}\right)$ \\
& $\left(\bar{\pi}_{1}, p_{1}^{d} k_{2}, p_{1}^{d} k_{3}\right)$ & $\left(\bar{\pi}_{1}, p_{1}^{d} k_{2}, p_{1}^{d} k_{3}\right)$ & $\left(\bar{\pi}_{1}, p_{1}^{d} k_{2}, \widetilde{p} k_{3}\right)$ \\
& $\left(\bar{\pi}_{1}, p_{1}^{d} k_{2}, p_{1}^{d} k_{3}\right)$ & $\left(\bar{\pi}_{1}, p_{1}^{d} k_{2}, p_{1}^{d} k_{3}\right)$ & $\left(\bar{\pi}_{1}, p_{1}^{d} k_{2}, p_{1}^{d} k_{3}\right)$ \\
\hline \multirow{2}{*}{ Period 3 } & $\left(\bar{\pi}_{1}, \widetilde{p} k_{2}, p_{1}^{d} k_{3}\right)$ & $\left(\bar{\pi}_{1}, p_{1}^{m} k_{2}, p_{1}^{m} k_{3}\right)$ & $\left(\bar{\pi}_{1}, p_{1}^{m} k_{2}, p_{1}^{m} k_{3}\right)$ \\
& $\left(\bar{\pi}_{1}, p_{1}^{m} k_{2}, p_{1}^{d} k_{3}\right)$ & $\left(\bar{\pi}_{1}, \widetilde{p} k_{2}, p_{1}^{d} k_{3}\right)$ & $\left(\bar{\pi}_{1}, p_{1}^{m} k_{2}, p_{1}^{m} k_{3}\right)$ \\
& $\left(\bar{\pi}_{1}, p_{1}^{d} k_{2}, p_{1}^{d} k_{3}\right)$ & $\left(\bar{\pi}_{1}, p_{1}^{d} k_{2}, p_{1}^{d} k_{3}\right)$ & $\left(\bar{\pi}_{1}, p_{1}^{d} k_{2}, p_{1}^{d} k_{3}\right)$ \\
\hline
\end{tabular}

Table 1: Timing in case of $k_{1} \leq D\left(p_{1}^{d}\right)-k_{2}$.

\begin{tabular}{|c|c|c|c|}
\hline Firm 2\3 & Period 1 & Period 2 & Period 3 \\
\hline \multirow{3}{*}{ Period 1 } & $\left(\bar{\pi}_{1}, p_{1}^{d} k_{2}, p_{1}^{d} k_{3}\right)$ & $\left(\bar{\pi}_{1}, p_{1}^{u} k_{2}, \widetilde{p} k_{3}\right)$ & $\left(\bar{\pi}_{1}, p_{1}^{u} k_{2}, \widetilde{p} k_{3}\right)$ \\
& $\left(\bar{\pi}_{1}, p_{1}^{u} k_{2}, p_{1}^{d} k_{3}\right),\left(\bar{\pi}_{1}, p_{1}^{d} k_{2}, p_{1}^{u} k_{3}\right)$ & $\left(\bar{\pi}_{1}, p_{1}^{d} k_{2}, p_{1}^{u} k_{3}\right)$ & $\left(\bar{\pi}_{1}, p_{1}^{d} k_{2}, p_{1}^{m} k_{3}\right)$ \\
& $\left(\bar{\pi}_{1}, p_{1}^{u} k_{2}, p_{1}^{d} k_{3}\right),\left(\bar{\pi}_{1}, p_{1}^{d} k_{2}, p_{1}^{u} k_{3}\right)$ & $\left(\bar{\pi}_{1}, p_{1}^{u} k_{2}, p_{1}^{d} k_{3}\right)$ & $\left(\bar{\pi}_{1}, p_{1}^{d} k_{2}, p_{1}^{u} k_{3}\right)$ \\
\hline \multirow{3}{*}{ Period 2 } & $\left(\bar{\pi}_{1}, \widetilde{p} k_{2}, p_{1}^{u} k_{3}\right)$ & $\left(\bar{\pi}_{1}, p_{1}^{m} k_{2}, p_{1}^{m} k_{3}\right)$ & $\left(\bar{\pi}_{1}, p_{1}^{m} k_{2}, p_{1}^{m} k_{3}\right)$ \\
& $\left(\bar{\pi}_{1}, p_{1}^{u} k_{2}, p_{1}^{d} k_{3}\right)$ & $\left(\bar{\pi}_{1}, p_{1}^{d} k_{2}, p_{1}^{d} k_{3}\right)$ & $\left(\bar{\pi}_{1}, p_{1}^{u} k_{2}, \tilde{p} k_{3}\right)$ \\
& $\left(\bar{\pi}_{1}, p_{1}^{d} k_{2}, p_{1}^{u} k_{3}\right)$ & $\left(\bar{\pi}_{1}, p_{1}^{u} k_{2}, p_{1}^{d} k_{3}\right),\left(\bar{\pi}_{1}, p_{1}^{d} k_{2}, p_{1}^{u} k_{3}\right)$ & $\left(\bar{\pi}_{1}, p_{1}^{d} k_{2}, p_{1}^{u} k_{3}\right)$ \\
\hline \multirow{3}{*}{ Period 3 } & $\left(\bar{\pi}_{1}, \widetilde{p} k_{2}, p_{1}^{u} k_{3}\right)$ & $\left(\bar{\pi}_{1}, p_{1}^{m} k_{2}, p_{1}^{m} k_{3}\right)$ & $\left(\bar{\pi}_{1}, p_{1}^{m} k_{2}, p_{1}^{m} k_{3}\right)$ \\
& $\left(\bar{\pi}_{1}, p_{1}^{m} k_{2}, p_{1}^{d} k_{3}\right)$ & $\left(\bar{\pi}_{1}, \widetilde{p} k_{2}, p_{1}^{u} k_{3}\right)$ & $\left(\bar{\pi}_{1}, p_{1}^{m} k_{2}, p_{1}^{m} k_{3}\right)$ \\
& $\left(\bar{\pi}_{1}, p_{1}^{u} k_{2}, p_{1}^{d} k_{3}\right)$ & $\left(\bar{\pi}_{1}, p_{1}^{u} k_{2}, p_{1}^{d} k_{3}\right)$ & $\left(\bar{\pi}_{1}, p_{1}^{d} k_{2}, p_{1}^{d} k_{3}\right)$ \\
\hline
\end{tabular}

Table 2: Timing in case of $k_{1}>D\left(p_{1}^{d}\right)-k_{2}$.

Checking both tables, we can see that firm 1 achieves the same expected profit in each case. Studying both tables carefully, we obtain the following subgame-perfect equilibria of the three-period timing game. 
Theorem 1. Under efficient rationing and Assumptions 1-4 the timing game, in which the three firms can select between three periods to set their prices and thereafter (already knowing in which period the three firms will set their prices) the firms set their prices, has the following two types of subgame-perfect equilibria:

1. The large firm moves before the small firms and all of these solutions are payoff equivalent.

2. (a) If $k_{1} \leq D\left(p_{1}^{d}\right)-k_{2}$, then the large firm moves (not neccesarilly alone) in the last period.

(b) If $k_{1}>D\left(p_{1}^{d}\right)-k_{2}$, then the large firm moves with at least another small firm in the last period.

Based on the tables it can be checked that the two types of solutions given in Theorem 1 fully determine the set of subgame-perfect equilibrium solutions of the three-period timing game. Observe that the Pareto-efficient outcome would be a type 1 solution.

An extension of the model in the spirit of Deneckere and Kovenock (1992) in which waiting is costly and the firms could choose between many time periods would result in having the large firm as the first mover and the small firms as the second movers. Since then the large firm maximizes profit with respect to its residual demand curve and the small firms follow with the same price, we obtain a game-theoretic microfoundation of the dominant firm model of price leadership based on capacity-constrained BertrandEdgeworth triopolies.

\section{Concluding remarks}

In this paper we extended a result by Deneckere and Kovenock (1992) from duopolies to triopolies. Our findings strengthen their game-theoretic microfoundation of the dominant firm model of price leadership.

The extension of our results to the general oligopolistic case seems to be still out of reach. In case of $n$ periods and $n$ firms this would require the solution of many games with different exogenously given orderings of moves from which many of these have multiple decision periods with at least two firms moving simultaneously. Solving, for example, the game with an exogenously given ordering of moves in which two firms move in the first period and two in the second period in case of four firms, seems to be a challenging problem. However, we plan to work on this question in future research and we believe that partial results can be achieved.

\section{References}

Allen, B., And M. Hellwig (1993): "Bertrand-Edgeworth Duopoly with Proportional Demand," International Economic Review, 34, 39-60.

BAGH, A. (2010): "Variational Convergence: Approximation and Existence of Equilibria in Discontinuous Games," Journal of Economic Theory, 145, 1244-1268.

Beckmann, M. (1965): "Bertrand-Edgeworth Duopoly Revisited," in Operations Research-Verfahren, Vol. III, ed. by R. Henn, pp. 55-68. Hain, Meisenheim. 
Boyer, M., and M. Moreaux (1987): "Being a Leader or a Follower: Reflections on the Distribution of Roles in Duopoly," International Journal of Industrial Organization, 5, 175-192.

Cheviakov, A., And J. Hartwick (2005): "Beckmann's Bertrand-Edgeworth duopoly example revisited," International Game Theory Review, 7, 1-12.

Dastidar, K., And D. FurTh (2005): "Endogenous price leadership in a duopoly: Equal products, unequal technology," International Journal of Economic Theory, 1, 189-210.

Davidson, C., and R. Deneckere (1986): "Long-run Competition in Capacity, Shortrun Competition in Price and the Cournot Model," Rand Journal of Economics, 17, 404-415.

De Francesco, M., and N. Salvadori (2010): "Bertrand-Edgeworth Games under Oligopoly with a Complete Characterization for the Triopoly," Munich Personal RePEc Archive, MPRA Paper No. $2408 \%$.

De Frutos, M.-N., and N. Fabra (2011): "Endogenous capacities and price competition: The role of demand uncertainty," International Journal of Industrial Organization, 29, 399-411.

Deneckere, R., And D. Kovenock (1992): "Price Leadership," Review of Economic Studies, 59, 143-162.

Dowrick, S. (1986): "von Stackelberg and Cournot Duopoly: Choosing Roles," Rand Journal of Economics, 17, 251-260.

GAL-Or, E. (1985): "First Mover and Second Mover Advantages," International Economic Review, 26, 649-653.

Gangopadhyay, S. (1993): "Simultaneous vs Sequential Move Price Games: A Comparison of Equilibrium Payoffs," Indian Statistical Institute Discussion Paper No. 93-01.

Hamilton, J., and S. Slutsky (1990): "Endogenous Timing in Duopoly Games: Stackelberg or Cournot Equilibria," Games and Economic Behavior, 2, 29-46.

Hirata, D. (2009): "Asymmetric Bertrand-Edgeworth Oligopoly and Mergers," B.E. Journal of Theoretical Economics, 9, "Article 22".

HviID, M. (1991): "Capacity constrained duopolies, uncertain demand and nonexistence of pure strategy equilibria," European Journal of Political Economy, 7, 183-190.

Kreps, D. M., and J. A. Scheinkman (1983): "Quantity Precommitment and Bertrand Competition Yield Cournot Outcomes," Bell Journal of Economics, 14, 326-337.

LePore, J. (2012): "Cournot outcomes under Bertrand-Edgeworth competition with demand uncertainty," Journal of Mathematical Economics, 48, 177-186.

Levitan, R., And M. Shubik (1972): "Price Duopoly and Capacity Constraints," International Economic Review, 13, 111-122.

Matsumura, T. (1999): "Quantity-setting Oligopoly with Endogenous Sequencing," International Journal of Industrial Organization, 17, 289-296. 
_ (2002): "Market Instability in a Stackelberg Duopoly," Journal of Economics (Zeitschrift für Nationalökonomie), 75, 199-210.

Osborne, M. J., And C. Pitchik (1986): "Price Competition in a Capacity-Constrained Duopoly," Journal of Economic Theory, 38, 238-260.

Reynolds, S., And B. Wilson (2000): "Bertrand-Edgeworth competition, demand uncertainty, and asymmetric outcomes," Journal of Economic Theory, 92, 122-141.

TASnÁd, A. (2010): Timing of Decisions in Oligopoly Games. VDM Publishing House, Saarbrücken, Germany.

van Damme, E., And S. HuRkens (1999): "Endogenous Stackelberg Leadership," Games and Economic Behavior, 28, 105-129. $404-420$.

(2004): "Endogenous Price Leadership," Games and Economic Behavior, 47,

Vives, X. (1986): "Rationing Rules and Bertrand-Edgeworth Equilibria in Large Markets," Economics Letters, 21, 113-116.

- (1999): Oligopoly Pricing: Old Ideas and New Tools. MIT Press, Cambridge MA.

von Stengel, B. (2010): "Follower payoffs in symmetric duopoly games," Games and Economic Behavior, 69, 512-516.

Yano, M., and T. Komatsubara (2006): "Endogenous price leadership and technological differences," International Journal of Economic Theory, 2, 365-383.

$80 \%$

(2012): "Price Competition Or Tacit Collusion," KIER Discussion Paper No. 